\title{
THE IMPACT OF BREASTFEEDING PATTERNS ON REGIONAL DIFFERENCES IN INFANT MORTALITY IN GERMANY, 1910
}

\author{
Hallie J. KINTNER \\ University of Michigan, Ann Arbor, MI, USA *
}

Received September 1986, final version received September 1987

\begin{abstract}
This paper examines the impact of breastfeeding practices on the large regional differences in infant mortality in Germany around 1910. Breastfeeding is strongly negatively associated with infant mortality and remains so after controlling for public health measures and for demographic, economic, and social factors that also affect infant mortality. But it contributes much less to regional differences in infant mortality than do access to medical care, percentage illegitimate and marital fertility. Breastfeeding is less important than these other factors because it affects fewer causes of death and has a smaller impact on cause-specific infant mortality rates.
\end{abstract}

\section{Résumé. L'impact des caractéristiques de l'allaitement sur les différences régionales de mortalité infantile en Allemagne vers 1910}

L'auteur étudie l'impact des pratiques d'allaitement sur les grandes différences régionales de mortalité infantile observées en Allemagne aux alentours de 1910. Il existe une association fortement négative entre l'allaitement et la mortalité infantile, même quand on contrôle les facteurs démographiques, économiques, sociaux et de politique sanitaire, qui, eux aussi, affectent la mortalité infantile. Mais les différences régionales de mortalité infantile s'expliquent nettement moins par l'allaitement que par l'accessibilité des soins médicaux, le taux d'illégitimité des naissances et la fécondité légitime. L'allaitement est un facteur de moindre importance que ceux-ci parce qu'il n'a d'impact que sur un petit nombre de causes de décès, et un faible impact sur les taux de mortalité infantile par cause.

* Acknowledgements: I am grateful to the German Academic Exchange Service and the Rackham Graduate School of the University of Michigan for supporting data collection, to John Knodel and Arthur Imhof for providing some data sources, and to Ron Lesthaeghe for sending some bibliographic materials. Doug Kononen, Monica Liebert, and the anonymous referees made helpful comments. An earlier version of this paper was presented at the annual meeting of the Population Association of America, Philadelphia, 1979.

Author's current address: Operating Sciences Department, General Motors Research Laboratories, Warren, MI 48090-9057, USA. 


\section{Introduction}

During the late nineteenth and early twentieth centuries infant mortality in Germany was distinguished from that of other European countries by several features, including extensive regional variation. Infant mortality levels within Germany displayed a range as great as the difference between contemporary more and less developed countries. In 1908-1912, for instance, the infant mortality rate for German administrative areas. ranged from 78 to 276 infant deaths per 1,000 live births [Kintner (1982)] (fig. 1).

What factors accounted for these differences? Recently, investigators have debated how much regional breastfeeding practices contributed to regional differences in infant mortality and marital fertility in Belgium and the Netherlands [Vandenbroeke et al. (1983), Hofstee (1983), Lesthaeghe (1983)]. These researchers could not estimate the impact of breastfeeding because no quantitative information on infant feeding practices was available. Since breastfeeding practices in Germany during the early twentieth century were well documented, this paper examines the impact of breastfeeding on regional differences in infant mortality in Germany. Multivariate statistical techniques are used to control for the influence of other determinants of infant mortality, such as marital fertility, economic development, and public health measures. The paper also focuses on the biological mechanisms through which breastfeeding and other determinants of infant mortality operate, by examining their contribution to regional differences in the causes of infant death.

\section{Regional variation in infant mortality and breastfeeding}

Although on average three-quarters of the infants in an administrative area were breastfed, sharp regional differences in both the prevalence and duration of breastfeeding were present in Germany around 1910 [Kintner (1985), Knodel and Van de Walle (1967)]. In contrast to southeastern Germany where most infants were never breastfed, in northwestern Germany (aside from cities such as Berlin, Hamburg and Bremen), the prevalence of breastfeeding was quite high (fig. 2). The percentage of infants ever breastfed ranged from 25 to 95 per cent. The same patterns are present for the average duration of breastfeeding 


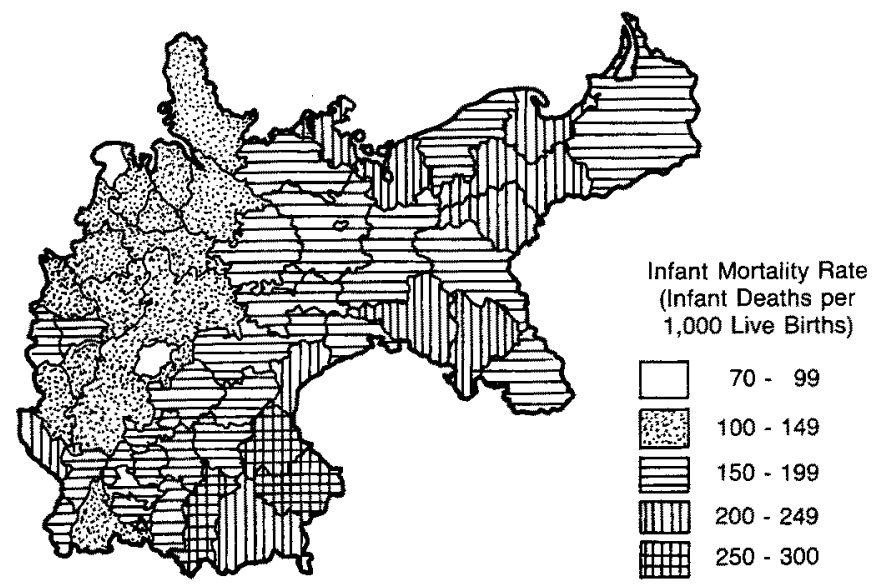

Fig. 1. Regional variation in infant mortality, Germany, 1908-1912.

(based on all infants). The average period of breastfeeding in 34 administrative areas around 1910 was 5.8 months, twice as long as the average in 117 districts in Bavaria, a region known for the custom of early weaning or never breastfeeding [Kintner (1985)].

Regional variation in breastfeeding practices corresponds well with regional variation in infant mortality (compare fig. 1 and 2). Nearly all infants were breastfed in northwestern Germany, the area of lowest

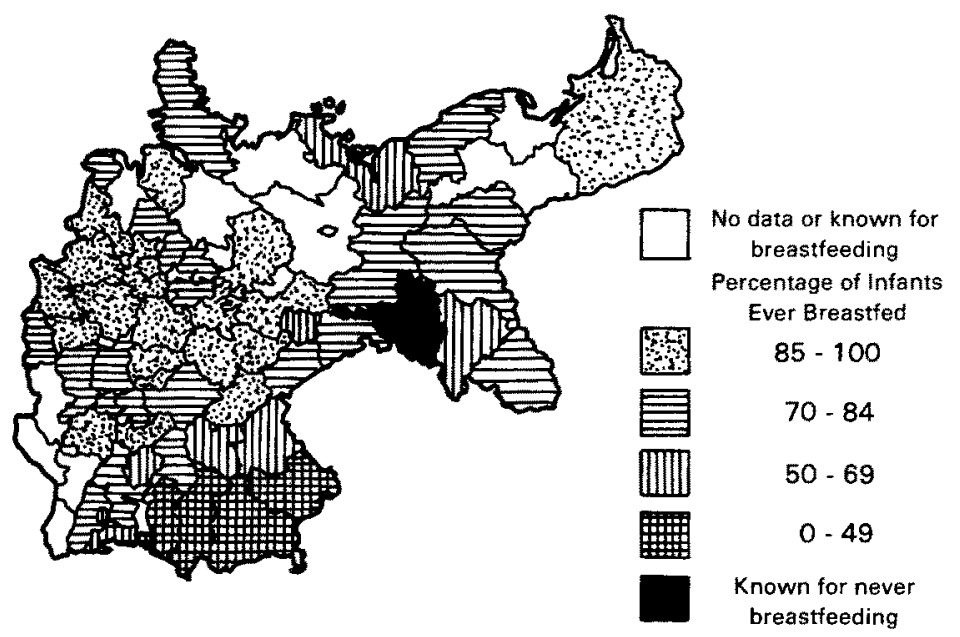

Fig. 2. Percentage of infants ever breastfed, 56 German administrative areas, 1903-1909. 
infant mortality. Areas in southeastern Germany, where most infants were never breastfed, experienced the highest infant mortality. However, the association is not perfect. Some urban areas, such as Hamburg, Bremen and Berlin, that had a sizeable percentage of infants who were never breastfed, had only low or moderate (for that time) levels of infant mortality. This suggests that other factors, which are reviewed next, also contributed to regional differences in infant mortality.

\section{A model of the determinants of infant mortality in Germany}

Breastfeeding and other factors have been incorporated into a theoretical model of the determinants of infant mortality in Germany (displayed in fig. 3).

The model consists of two structural equations, one predicting infant mortality (discussed next) and the other predicting marital fertility (to be discussed later). The double arrow between infant mortality and marital fertility indicates that they may affect each other simultaneously.

\subsection{Infant mortality}

Fig. 3 implies that infant mortality is a function of economic development, access to medical care, marital fertility, percentage Catholic, infant feeding practices, medical technology, population density, three public health measures (water systems, sewerage systems, and infant welfare centres) and the proportion of births that are illegitimate.

Most of these factors have been emphasized in explanations of mortality declines. The demographic transition posits a negative relationship between economic development and mortality levels. Beaver (1973) argues that improvements in the quality and quantity of cow's

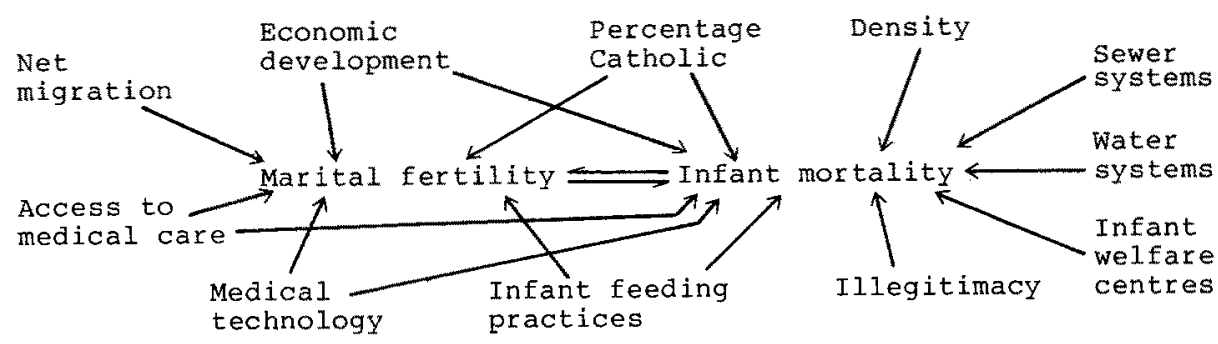

Fig. 3. Model of the determinants of infant mortality in Germany. 
milk as a substitute for breastmilk bore responsibility for infant mortality declines. Aykroyd and Kevany (1973) have attributed declines in infant mortality to a complex of factors including public health measures, the improved safety of cow's milk, the infant welfare movement, and increased access to medical care. Changes in fertility levels and reproductive patterns have also been considered major determinants of infant mortality declines [Reves (1985), Rott (1929)]. Improvements in medical technology, such as hygienic delivery rooms and intravenous therapy for diarrhoeal diseases, may also have made a contribution [McKeown (1976)].

The composition of births by legitimacy is known to have been associated with areal variation in infant mortality within Germany [Knodel (1974)]. Proportion Catholic is included not only because Catholics had high fertility but also because they tended to register stillbirths as infant deaths, thereby inflating the recorded infant mortality rate [Frey (1923), Knodel (1975)]. Population density is included because it has generally been found to be positively related to mortality in historical studies [see, for example, Condran and Crimmins-Gardner (1978)].

The substantial survival advantage of breastfed infants over artificially fed infants has been noted in historical European and American populations as well as in contemporary less-developed countries [see, for instance, Knodel (1977), Woodbury (1925), Cunningham (1981), and Jason et al. (1984)]. Breastmilk is not only nutritionally ideal for the growing child but also transmits needed immunities from the mother [Chandra (1978)] and is relatively sterile. The chances of breastfed infants surviving to age one vary from 1 to 30 per cent higher than those of artificially fed infants [Knodel (1977)]. Though some have argued that the influence of breastfeeding may have been overstated because of biases in study design, a recent study demonstrated that 'even when these biases are dealt with, unsupplemented breastfeeding appears more beneficial than supplemented breastfeeding' [Habicht et al. (1986)].

While it is doubtful that areal and temporal differences in infant mortality rates are due solely to any one factor, it is difficult to anticipate the relative contribution of each variable. Variables that influence primarily areal variation and population density are, however, expected to have relatively minor effect.

Infant mortality is expected to be negatively related to the preva- 
lence and duration of breastfeeding. It may be curvilinearly related to breastfeeding because after six months breastmilk can supply only part of an infant's nutritional requirements (Jelliffe and Jelliffe (1978)]. Thus fully breastfeeding for longer than six months (without introduction of supplemental foods) may actually increase infant mortality. Infant mortality is hypothesized to be negatively related to access to medical care, medical technology, and the three public health factors, and positively related to the remaining factors, including economic development. It is also likely that the effect of breastfeeding interacts with the quality of drinking water and the availability of sewerage facilities [Lesthaeghe (1983), DaVanzo and Habicht (1986)]. For example, breastfeeding has been shown to be more strongly associated with infant survival in houses without piped water or toilet sanitation in contemporary Malaysia [Butz, Habicht, and DaVanzo (1984)].

These determinants of infant mortality are expected to influence regional variation in infant mortality by affecting regional variation in one or more causes of infant death. Variation in the incidence of certain diseases of infancy (mostly prematurity and immaturity) is related to maternal nutritional status and reproductive patterns, including age of mother, rapidity of childbearing and number of children ever born [Lechtig et al. (1978), United Nations (1954)]. Diarrhoeal diseases are associated with insufficient and/or contaminated food and water, warm climates, malnutrition and poor sanitary conditions [Preston (1976)]. Influenza/pneumonia/bronchitis are related to nutritional status, cold climates, and poor housing conditions. Diarrhoea and influenza/pneumonia/bronchitis are closely related. Several studies have shown that mortality from air-borne diseases is often the result of debilitation originally caused by bouts of diarrhoeal disease [Preston and Van de Walle (1978)]. The survival disadvantage of illegitimate German infants operated mainly through certain diseases of infancy and digestive diseases and somewhat through infectious and respiratory diseases [Prinzing (1931)]. Proportion Catholic is hypothesized to operate through certain diseases of infancy (because of the misregistration of stillbirths) and possibly also through infectious and parasitic diseases, because of large family size.

\subsection{Marital fertility}

The theoretical model in fig. 3 allows for the possibility that marital fertility and infant mortality are mutually related. While there is much 
evidence that marital fertility affects infant mortality [e.g., Reves (1985), Rott (1929)], and that infant mortality affects marital fertility [Preston (1978)], few studies have appreciated the complexity of this relationship. The equation for marital fertility includes net migration, access to medical care, medical technology, proportion Catholic, economic development, and infant feeding practices. German marital fertility was negatively related to economic development and positively related to the proportion Catholic [Knodel (1974), Richards (1977)]. Infant feeding practices are included in this equation because the duration of breastfeeding is directly related to the length of postpartum amenorrhea [Van Ginneken (1974)]. Net migration is included because out-migration may be an alternative to fertility reduction as a response to population pressure [Davis (1963)]. Access to medical care and medical technology are included because both would affect fecundity by improving the health status of women. Improvements in water and sewerage systems probably contributed little to the health of women in the reproductive ages, if the low incidence of the causes of death associated with these factors is a valid indicator of morbidity in these ages. They are, therefore, not included in the equation. Population density is also excluded from this equation because, although it is negatively related to fertility in many animal populations, the nature of the relation is not clear-cut in human populations [Galle and Gove (1978)].

\section{Data and operationalization of variables}

Our analyses are based on data from 54 administrative areas in 1910. The administrative areas used here are a combination of smaller states, such as Lippe, Bremen, and Hamburg, and of middle-level political units (Regierungsbezirke) for the larger states, including Prussia, Bavaria, Baden, Saxony, and Hessen. They are described in more detail in Knodel's monograph [Knodel (1974)]. Seventeen of the original 71 administrative areas were excluded because of lack of data. ${ }^{1}$

Table 1 displays definitions, abbreviations, and data sources for the variables. The exact indicators used were chosen because of their

\footnotetext{
1 The following administrative areas were excluded: Danzig, Marienwerder, Potsdam, Liegnitz, Lüneburg, Trier, Sigmaringen, Mecklenburg, Herzogtum Oldenburg, Furstentum Lübeck, Birkenfeld, Braunschweig, Anhalt, Schaumburg-Lippe, Unterelsass, Oberelsass, and Lothringen.
} 


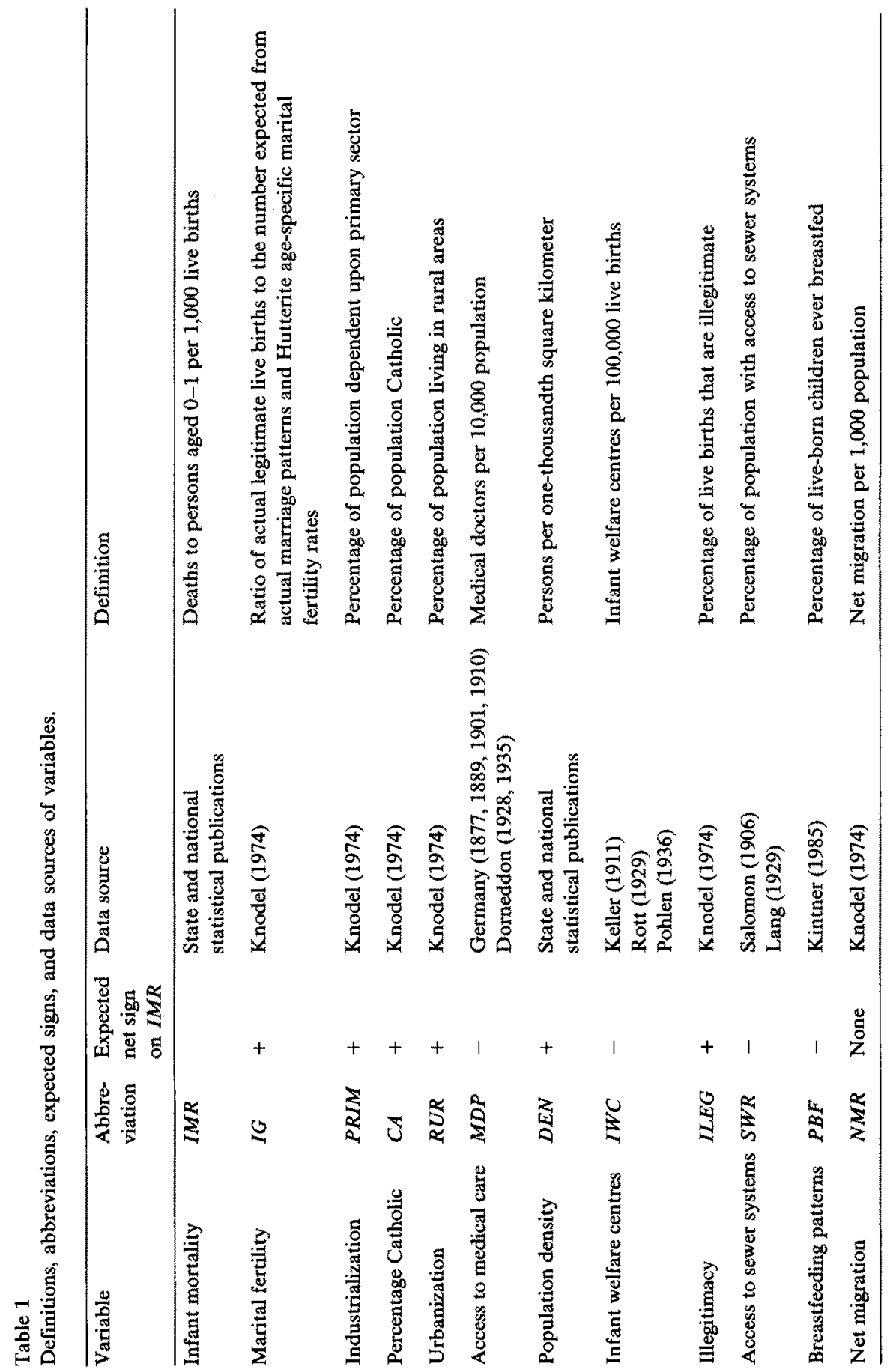


availability or because using alternative ones would have required considerable interpolation. Rates are averaged over the five-year period (1908-1912) to reduce yearly fluctuations. Economic development is represented by industrialization and urbanization.

Infant feeding practices are measured by the prevalence of breastfeeding (percentage of live-born children ever breastfed) rather than by the average duration of breastfeeding because more data on the former variable is available. The average duration (based on all infants) is highly positively correlated with the prevalence of breastfeeding [Kintner (1985)]. Data on the incidence of breastfeeding was compiled from several different sources and is discussed in detail elsewhere (ibid.).

Information on the causes of infant death was taken from state and national statistical publications. A uniform cause-of-death classification was developed to combine the various state and national classification schemes [Kintner (1986)]. This paper focuses on four major groups of causes of death that are mutually exclusive and all-inclusive: certain diseases of infancy $(C D I)$, water-borne diseases (WAT), air-borne diseases $(A I R)$, and other causes of death $(O T H)$. These groups were chosen because they distinguish two major forms of disease transmission and the conditions associated with mortality shortly after birth. Water-borne diseases include diarrhoeal diseases, cholera, and typhoid. Air-borne diseases consist of respiratory diseases and tuberculosis as well as other infectious and parasitic diseases transmitted by air, such as whooping cough.

This original classification groups cramps, a poorly defined cause of infant death, with other ill-defined conditions in other causes of death $(O T H)$. A modification of this classification scheme is also presented in which most deaths from cramps are considered as diarrhoeal disease and grouped with water-borne disease $\left(W A T^{*}\right)$. The corresponding category of other causes of death without cramps is designated $\left(O T H^{*}\right)$.

\section{Methods}

The results are presented in three sections. The first section presents simple descriptive statistics and the zero-order correlation between breastfeeding and infant mortality. This section also analyzes the correlations between infant mortality and each of the other explanatory variables. 
The second section examines how much breastfeeding influences infant mortality after controlling for the other variables in the model. This relationship is examined using a recursive model of infant mortality that does not allow for the simultaneity between infant mortality and marital fertility: ${ }^{2}$

$$
\begin{aligned}
\operatorname{logit} I M R= & b_{0}+b_{1} I G+b_{2} P R I M+b_{3} R U R+b_{4} C A+b_{5} M D P \\
& +b_{6} S W R+b_{7} I W C+b_{8} I L E G+b_{9} I F P+b_{10} D E N
\end{aligned}
$$

Estimates of some of the coefficients may be biased because no measures are available for medical technology or water systems, which were included in the structural equation for infant mortality in fig. 3 [Kmenta (1971)]. These omissions are, however, not likely to affect the coefficient for the percentage ever breastfed. Generally, omitted variables influence most the coefficients of the variables with which they are closely correlated (ibid.). The percentage ever breastfed is unlikely to be correlated with medical technology. It is probably associated with water systems because some substitutes for breastmilk were prepared with drinking water [Kintner (1985)]. But the bias is likely to be small because eq. (1) does control for sewerage systems. In Germany, development of water systems paralleled that for sewerage systems [Kintner (1982)]. Furthermore, an essential mortality-reducing aspect of water systems is separation of drinking water from sewage.

The second section also examines the impact of breastfeeding on regional variation in marital fertility by estimating the following recursive model:

$$
\begin{aligned}
I G= & g_{0}+g_{1} I M R+g_{2} P R I M+g_{3} R U R+g_{4} C A+g_{5} M D P \\
& +g_{6} N M R+g_{7} I F P .
\end{aligned}
$$

Since this equation also excludes medical technology, for which no measure is available, the estimates of the coefficients may be biased

2 The proposed simultaneous equation model could not be estimated using full information maximum likelihood estimation by LISREL [Joreskog and Sorbom (1978)]. Although the theoretical model satisfies both the order and rank conditions for identification [Kmenta (1971)], it is not identified using the sample data [Kintner (1982)]. Note that estimation of this system using OLS could result in biased and inconsistent estimates of the coefficients for marital fertility and infant mortality [Kmenta (1971)]. 
[Kmenta (1971)]. Again this omission is not likely to affect the coefficient of the percentage ever breastfed, however, because the latter is unlikely to be correlated with medical technology.

The third section identifies the causes of death responsible for regional differences in infant mortality and analyzes the impact of breastfeeding on the causes of infant death after controlling for the other determinants of infant mortality.

To estimate the extent to which a particular cause of death contributes to regional variation in infant mortality, equations of the following form were estimated:

$\operatorname{CSIMR}_{i}=a_{i}+b_{i} I M R$

where $C S I M R_{i}$ is the cause-specific infant mortality rate of cause $i$ (infant deaths due to cause $i$ per 1,000 live births) and $I M R$ is the infant mortality rate from all causes combined. Aside from rounding error, the $a_{i}$ sum to zero and the $b_{i}$ sum to 1.0 [Espenshade (1973) cited in Preston (1976)].

Eq. (1) was estimated separately for each cause-specific infant mortality rate in order to examine the impact of breastfeeding on the causes of infant death controlling for the other determinants of infant mortality.

\section{Descriptive statistics}

By 1910 , Germany had completed much of the transition from a predominantly rural agrarian state to a highly urban industrialized society. On average only $30 \%$ of the population in an administrative area depended on the primary sector (agriculture, mining and forestry) and less than half the population (44\%) lived in rural areas (table 2). Population density had risen from 0.35 persons per square kilometer ${ }^{3}$ in 1871 to 0.82 in 1910 . The number of physicians per 10,000 inhabitants was moderate (about five) while the number of infant welfare and mother advising centres was very low (less than one per 1,000 live births). About 30 per cent of the population in an administrative area

\footnotetext{
${ }^{3}$ Population density is measured as persons per one-thousandth square kilometer in the regression analyses so that estimated coefficients are all of roughly the same magnitude.
} 


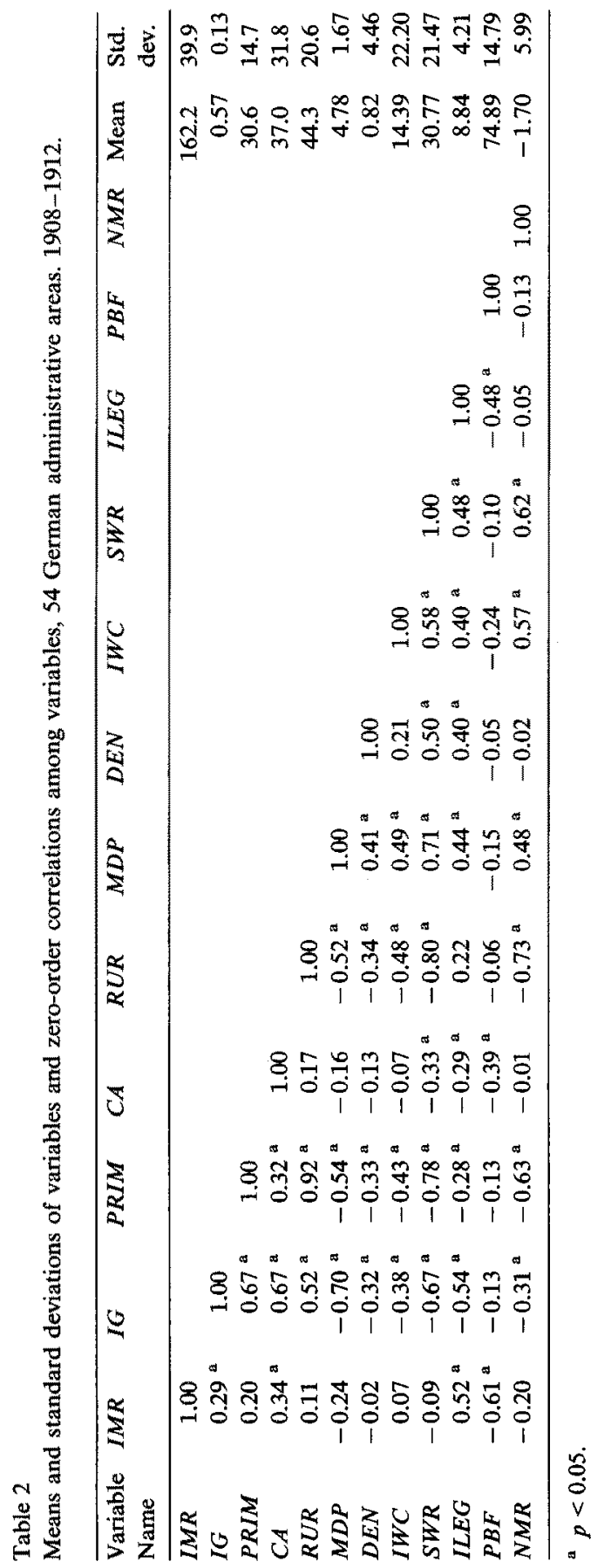


had access to sewerage systems. Infant mortality rates were high (162 infant deaths per 1,000 live births) and had only begun to decline [Kintner (1982)]. Marital fertility was also still fairly high, averaging about half the level of the Hutterites, but had already declined to $71 \%$ of the 1871 level [Knodel (1974)]. About nine per cent of all live births were illegitimate, which reflects high illegitimate fertility in Germany relative to the rest of Europe [Shorter, Knodel and Van de Walle (1971)]. About one third of the population was Catholic (35\%), a figure that had remained constant since 1871 [Knodel (1974)]. More people were emigrating than immigrating but at a lower rate than that observed between 1880 and the early 1890 s (ibid.). The mean level of most variables is representative of Germany. ${ }^{4}$

As expected, the percentage of infants ever breastfed is strongly negatively related to infant mortality $(r=-0.61, p<0.05)$. This correlation is similar to that found by Knodel and Van de Walle (1967) using data on different administrative areas in Germany. The correlations between infant mortality and industrialization, urbanization, access to medical care, density, sewerage systems, and infant welfare centres, respectively, are not statistically significant from zero.

The prevalence of breastfeeding is not significantly associated with marital fertility $(r=-0.13, p>0.05)$. As hypothesized, marital fertility is positively related to the percentage dependent on the primary sector, percentage Catholic and percentage rural. Contrary to expectations, it is negatively related to access to medical care and net migration.

Several explanatory variables are closely correlated. For instance, the measures of urbanization $(R U R)$ and industrialization $(P R I M)$ have a correlation of 0.92 . The percentage of the population with access to sewerage systems $(S W R)$ is also closely associated with both variables, as might be expected since sewer systems were first constructed in industrialized urban areas. This degree of multicollinearity is high enough to result in imprecise estimates of the variances of the regression coefficients, which affects significance tests [Kmenta (1971)]. To overcome this problem the indicators of industrialization (PRIM) and access to sewerage systems $(S W R)$ were not included in the final

\footnotetext{
${ }^{4}$ The largest discrepancy between the sample and national figures is for infant mortality. The average infant mortality rate in an administrative area in the sample is 162 , slightly lower than the national infant mortality rate of 169.9 [Kintner (1982)].
} 
regression equation. These variables rather than others [e.g., urbanization $(R U R)$ ] were deleted because they are less closely associated with infant mortality and more closely associated with other explanatory variables.

\section{The impact of breastfeeding after controlling for other variables}

This section examines the effect of breastfeeding after controlling for the other determinants of German infant mortality. First, however, the impact of the other determinants is examined.

The first equation of table 3 presents ordinary least squares (OLS) estimates of the coefficients of a model where the infant mortality rate, transformed as a logit ${ }^{5}$, is regressed on marital fertility, percentage Catholic, percentage rural, access to medical care, population density, infant welfare centres, and percentage illegitimate. No breastfeeding variables were included. As expected, marital fertility, percentage Catholic, and the level of illegitimacy are positively related to infant mortality and access to medical care is negatively related to it. Contrary to expectations, population density and the percentage rural are both negatively related to infant mortality. The coefficients of all variables except infant welfare centres are statistically significant $(p<$ 0.05 ). Few infant welfare centres had been established by 1910 , so those that had been established may not have devised the most effective childcare methods by this time. This equation accounts for $82 \%$ of the variance in the logit of the infant mortality rate.

In the next equation, the infant mortality rate (transformed as logit) is regressed on the percentage ever breastfed, its square ${ }^{6}$ (abbreviated $P B F S Q$ ), the interaction between the prevalence of breastfeeding and the percentage with access to sewerage system ${ }^{7}(P B F S W R)$, as well as the variables in the first equation. The addition of these variables

${ }^{5}$ The mean and standard deviation of logit $I M R$ are -1.671 and 0.297 , respectively.

${ }^{6}$ The quadratic term is represented by the square of $(P B F-74.89)$. The mean is subtracted from the percentage ever breastfed to reduce the correlation between the linear and quadratic terms. The mean and standard deviation of this variable are 212.7 and 462.7 .

7 This interaction is represented by a dummy variable scored one if breastfeeding was below $60 \%$ and the percentage of the population with access to sewer systems was less than 30 , and zero otherwise. Various formulations of this interaction were estimated but none was statistically significant. 
significantly increases the amount of explained variance. ${ }^{8}$ The interaction term is not significantly different from zero. Since this interaction term is highly correlated with the other two breastfeeding variables, its presence may be adversely influencing the significance of these terms.

Equation $\mathrm{C}$ of table 3, therefore, excludes the interaction term. As before, the increment in explained variance is statistically significant, though quite small. Unlike in equation $\mathrm{B}$, the coefficients of both breastfeeding terms are significant. ${ }^{9}$ However, the signs of the coefficients are not in the expected direction. If the prevalence of breastfeeding diminishes infant mortality until about the sixth month, it would be expected that the linear term would be negative and the quadratic term would be positive. Here both terms are negative, indicating that prolonged breastfeeding reduces infant mortality even further. This effect would be plausible if foods given to infants after age six months were less nutritionally adequate than breastmilk. While a full nutritional comparison of breastmilk and various infant foods used historically has not been conducted, a review of foods typically given to infants in Germany at that time [Kintner (1985)] indicates this possibility is not out of the question. For instance, commercial infant foods typically contained less protein and more sugar than breastmilk (ibid.)

The coefficients in equation $C$ are difficult to interpret since they represent the change in logit $I M R$ due to a change of one unit in the explanatory variables. In column (4) of table 3 these coefficients have been transformed into the change in the infant mortality rate due to a change of one unit in the explanatory variable $(\mathrm{d} I M R)$ using the cumulative distribution function [Petersen (1985)]. Increasing the percentage ever breastfed by one unit reduces the infant mortality rate by 0.54 infant deaths per 1,000 live births (combining both the linear and quadratic terms and evaluating at the mean). In contrast, if the percentage illegitimate were hypothetically to increase by one, the infant mortality rate would rise by 10 infant deaths per 1,000 live births; and an increase of one physician per 10,000 population would lower the

\footnotetext{
8 The $F$-test for the significance of the increment in explained variance was used [Kmenta (1971)].

9 The stability of these results was investigated using regression diagnostic techniques for detecting outliers and influential cases [for a good review, see Bollen and Jackman (1985)]. These techniques suggested that the regression estimates were unduly influenced by four administrative areas. However, results are nearly robust to the omission of these administrative areas. Original results based on all cases are presented because there is no substantive reason to omit these four administrative areas, aside from their effect on the estimation.
} 


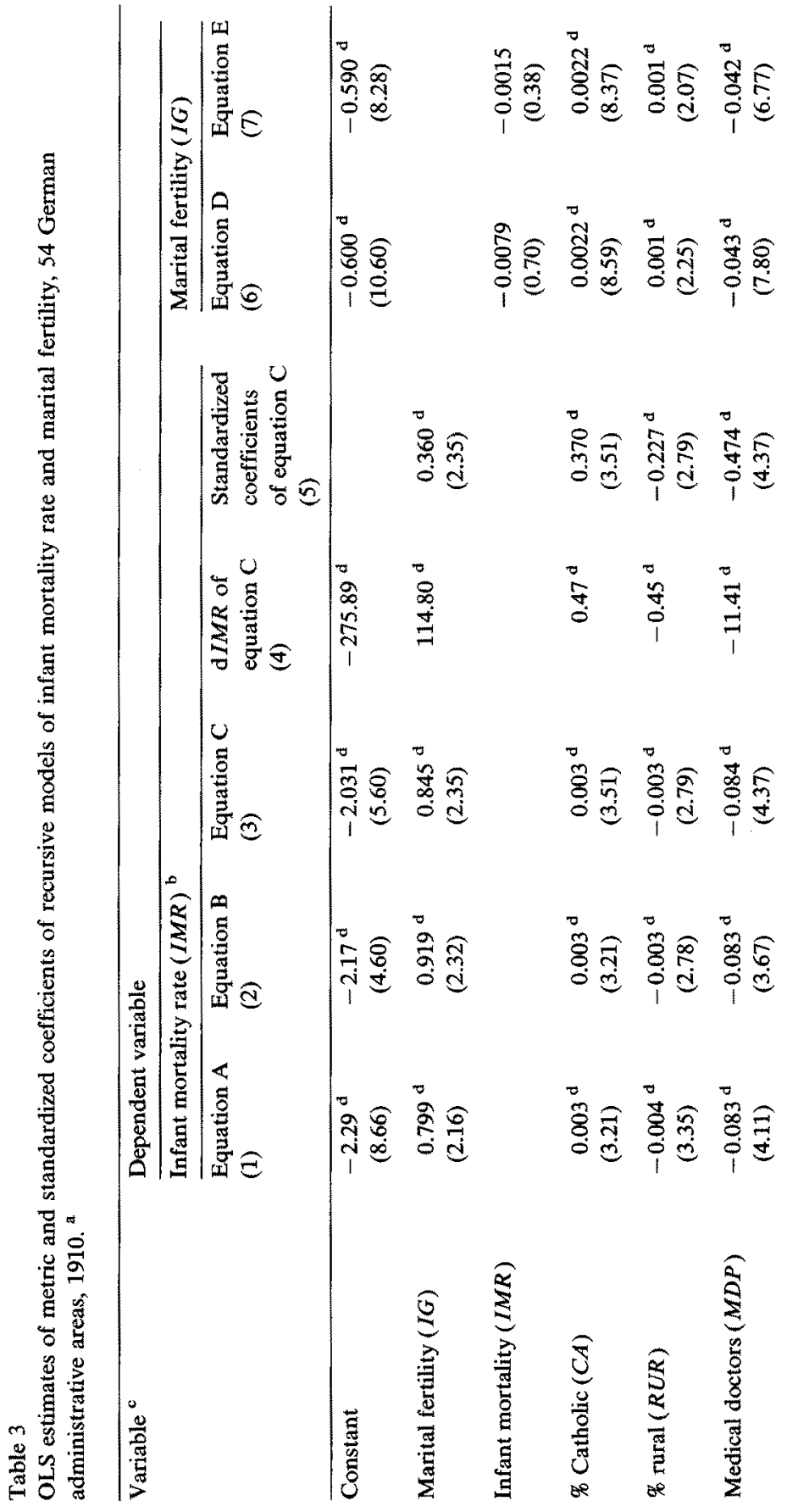


옹종 홓졍

ㅇํㅇ융

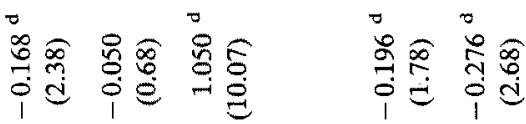

$\begin{array}{lllll}0 & 0 & 0 \\ i & 0 & 0 & 0 & 0 \\ i & 0 & 0 \\ i & 1 & 0\end{array}$

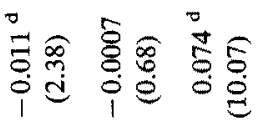

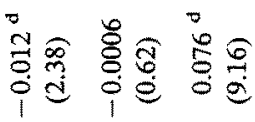

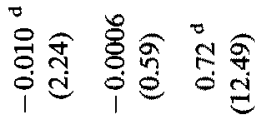

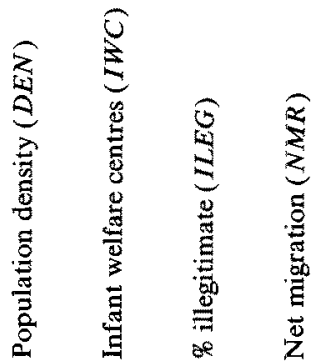

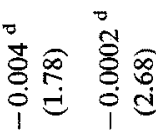

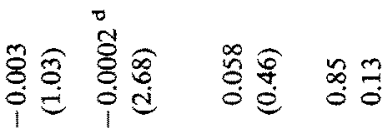

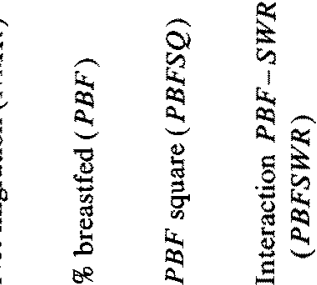

$\stackrel{\infty}{\infty} \stackrel{2}{0}$

$\stackrel{m}{\infty} \stackrel{n}{0}$

$\stackrel{\infty}{\infty}:$

$\infty$ 
infant mortality rate by eleven points. The effect of marital fertility is particularly large when viewed in terms of a one unit change in $I G$, as in table 3. It represents a decrease of 19.7 infant deaths per 1,000 live births for a one child reduction in the Total Fertility Rate. ${ }^{10}$

The coefficients in columns (3) and (4) cannot be used to determine the importance of breastfeeding relative to most of other variables since they are measured in different units. (Note, though, that percentage ever breastfed and percentage illegitimate share a common metric.) The impact of breastfeeding compared with that of the other factors can be examined in two different ways - standardized regression coefficients and elasticities. The standardized regression coefficients [column (5) of table 3] are the expected change in the infant mortality rate $(I M R)$, in standard deviation units, for an increment of one standard deviation in an explanatory variable, holding the other explanatory variables constant. Using this criterion, illegitimacy has by far the greatest impact on regional differences in infant mortality, followed by access to medical care, marital fertility and percentage Catholic. The standardized coefficient for the effect of breastfeeding, combining both the linear and the quadratic terms, is -0.2 , evaluated at the average percentage ever breastfed. ${ }^{11}$ This coefficient is much smaller than those for illegitimacy and access to medical care, perhaps because the standard deviation of the percentage ever breastfed is small relative to its mean (table 2).

The impact of breastfeeding is also small compared to that of other variables when viewed in terms of elasticities or the percentage change in $I M R$ per one per cent change in the explanatory variables. ${ }^{12}$ Here elasticities are discussed in terms of hypothetical proportionately equivalent $(20 \%)$ changes. When the observed average values are inserted into equation $\mathrm{C}$ of table 3 , the average infant mortality rate is predicted to be $162 .{ }^{13}$ In this equation the percentage ever breastfed averages

${ }^{10}$ Calculated using the approximation $T F R=11 \times I G \times 0.53$ [Richards (1977)].

11 The standardized regression coefficient for both terms combined was calculated by taking the partial derivative and multiplying by the ratio of the standard deviations of the percentage ever breastfed to that for the logit of the IMR [Stolzenberg (1979)].

${ }^{12}$ Since $\ln (p /(1-p))=\sum X_{i} b_{i}, p=\exp \left(\sum X_{i} b_{i}\right) /\left(1+\exp \left(\sum X_{i} b_{i}\right)\right)$, where $X_{i}$ are the explanatory variables, $b_{i}$ the estimated coefficients, and $i$ goes from 1 to 9 in equation $C$ of table 3 .

${ }^{13}$ To derive the average predicted $I M R$, predicted $I M R$ was first calculated separately for each administrative area using the procedure in the previous footnote and then averaged over the 54 cases. Since the logit transformation is non-linear, the value of $I M R$ does not equal average $I M R$ predicted by the weighted sum of variable means, where the weights are the regression coefficients. The sample mean is however estimated by averaging IMRs predicted by weighing variable values by coefficients and then averaging over all cases. 
74.89. If the average percentage ever breastfed rose to $90 \%$ and the means of the other variables stayed the same, the average $I M R$ is predicted to fall slightly, to $153 .{ }^{14}$ The impact of changes in breastfeeding is not as strong as that of proportionately equivalent changes in illegitimacy, access to medical care or marital fertility. For instance, if the mean percentage illegitimate were lowered from 8.8 to 7.1 per cent, the $I M R$ would fall by ten per cent to 145 . Similarly, if the average number of physicians per 10,000 population rose from 4.8 to 5.7 , the $I M R$ would fall to 151 , a $7 \%$ drop. If marital fertility fell from $57 \%$ of the level of the Hutterites to $45 \%$ of that level, the rate would be 149 , a $8 \%$ decline.

The relative importance of breastfeeding is further illustrated by comparing the impact of various socio-demographic changes between 1910 and 1933. During this time IMR fell from 162 to 71 infant deaths per 1,000 live births. A strong nationwide resurgence in the incidence of breastfeeding occurred between the two world wars, accompanied by a decline in the average duration of breastfeeding [Kintner (1985)]. Nationally, the percentage ever breastfed rose to $95 \%$ and the formerly large regional differences in breastfeeding patterns disappeared by 1937 (ibid.). How much of this decline was due to the resurgence in the incidence of breastfeeding? If the average percentage ever breastfed rose to $95 \%$ and the values of the other variables stayed at their 1910 level, the average $I M R$ is predicted to fall to 147 , a drop of $9 \%$. The increase in breastfeeding accounted for only a small portion (16\%) of the infant mortality decline during this period. In contrast, an increase in access to infant welfare centres to its 1933 level of 553.3 per 100,000 live births would lead to a $27 \%$ drop in infant mortality; the increase in access to physicians (to 6.68 per 10,000 population) would result in a $13 \%$ decline in infant mortality; and the dramatic decline in marital fertility (to $\mathrm{IG}=0.29$ ) would lead to an infant mortality rate $18 \%$ lower. Since the percentage illegitimate increased between 1910 and 1933, it did not contribute to the decline.

\footnotetext{
${ }^{14}$ This predicted IMR was not obtained by merely multiplying the value of percentage ever breastfed for each administrative area by 1.2 since this procedure leads to some cases with values exceeding one hundred per cent. Rather, percentage ever breastfed was raised by a greater amount in the areas where breastfeeding was least common. That is, percentage ever breastfed was multiplied by 2.26 for areas where less than half of all infants were breastfed, by 1.35 where $50-74 \%$ of infants were breastfed, by 1.173 where $75-82 \%$ of infants were breastfed, and by 1.05 where over $82 \%$ of infants were breastfed.
} 
Comparison of equations $\mathrm{A}$ and $\mathrm{C}$ in table 3 shows that the regression coefficients of the other variables are affected very little if the prevalence of breastfeeding is omitted from the equation. Since there is little such specification bias, researchers in countries without information on breastfeeding can examine the impact of other variables on regional differences in infant mortality with little worry that these estimates are biased.

The cause-of-death structure and the impact of breastfeeding on the causes of infant death will be examined next to determine why breastfeeding's contribution to regional differences is small compared to that of other factors. But first, the impact of breastfeeding on marital fertility is reviewed.

The effect of breastfeeding on marital fertility is examined in the last two columns of table 3. In equation $\mathrm{D}$, marital fertility is regressed on infant mortality, percentage Catholic, percentage rural, access to medical care and net migration. No breastfeeding terms are included. The coefficients for percentage Catholic, percentage rural and access to medical care are significant. The first two coefficients are positive, as was hypothesized. Contrary to expectations, though, access to medical care reduces marital fertility. The coefficients of infant mortality and migration are not significant. In equation $\mathrm{E}$, marital fertility is regressed on all the variables in the previous equation plus the percentage breastfed. Breastfeeding does not significantly affect marital fertility. This model explains $83 \%$ of the regional variation in marital fertility.

\section{Cause-of-death structure}

Regional differences in infant mortality rates are primarily due to water-borne diseases without cramps $(W A T)$, which are responsible for $45 \%$ of the regional variation in infant mortality (table 4 ). Certain diseases of infancy account for a quarter of the variation in infant mortality. Other and unknown diseases (including cramps) are responsible for $19 \%$ of the variation while air-borne diseases account for $11 \%$. The contribution of water-borne diseases remains the same even when deaths due to cramps are added to it, as can be seen by comparing the regression coefficient for water-borne diseases without cramps $(0.45)$ to that for water-borne diseases with cramps $(0.48)$.

The relatively small impact of breastfeeding on regional differences 
Table 4

Correlation coefficients and parameters of linear regression relating cause-specific infant mortality rates $(C S I M R)$ to the infant mortality rate $(I M R)$ from all causes combined, 54 German administrative areas, 1910. ${ }^{\text {a }}$

\begin{tabular}{|c|c|c|c|}
\hline \multirow{2}{*}{$\begin{array}{l}\text { Cause of } \\
\text { death }\end{array}$} & \multirow{2}{*}{$\begin{array}{l}\text { Coefficient } \\
\text { of } \\
\text { correlation }\end{array}$} & \multicolumn{2}{|c|}{$C S I M R=a+b I M R$} \\
\hline & & $a$ & $b$ \\
\hline Diseases of infancy $(C D I)$ & 0.77 & $\begin{array}{l}-0.0036 \\
(0.75)\end{array}$ & $\begin{array}{l}0.2501^{b} \\
(8.64)\end{array}$ \\
\hline Water-borne diseases (WAT) & 0.81 & $\begin{array}{l}-0.0250^{\mathrm{b}} \\
(3.31)\end{array}$ & $\begin{array}{l}0.4541^{b} \\
(10.05)\end{array}$ \\
\hline Air-borne diseases $(A I R)$ & 0.58 & $\begin{array}{l}0.0136^{b} \\
(3.86)\end{array}$ & $\begin{array}{l}0.1077^{b} \\
(5.11)\end{array}$ \\
\hline $\begin{array}{l}\text { Other diseases } \\
\text { (including cramps) }(O T H)\end{array}$ & 0.34 & $\begin{array}{l}0.0150 \\
(1.26)\end{array}$ & $\begin{array}{c}0.1881^{b} \\
(2.62)\end{array}$ \\
\hline Sum & & 0.000 & 1.000 \\
\hline $\begin{array}{l}\text { Water-borne diseases } \\
+ \text { cramps }\left(W A T^{*}\right)\end{array}$ & 0.86 & $\begin{array}{l}-0.0140 \\
(2.19)\end{array}$ & $\begin{array}{l}0.4783^{b} \\
(12.43)\end{array}$ \\
\hline $\begin{array}{l}\text { Other diseases } \\
\text { (excluding cramps) }\left(O T H^{*}\right)\end{array}$ & 0.42 & $\begin{array}{l}0.0041 \\
(0.51)\end{array}$ & $\begin{array}{l}0.1638^{b} \\
(3.37)\end{array}$ \\
\hline
\end{tabular}

a All rates are in decimal form. $T$-statistics are in parentheses.

${ }^{b}$ Coefficient is at least twice its standard error.

in infant mortality is surprising since regional differences in infant mortality are due primarily to water-borne diseases, which are thought to be closely linked to infant-feeding practices.

\section{The impact of breastfeeding on the causes of infant death}

This section examines the cause-of-death structure to see why breastfeeding contributes much less to regional differences in infant mortality than do access to medical care and illegitimacy. Three explanations are possible. Firstly, breastfeeding may exert a greater influence than other factors on those causes of death that account for relatively little of the regional differences in infant mortality. Secondly, breastfeeding may influence fewer causes of death or causes of death 


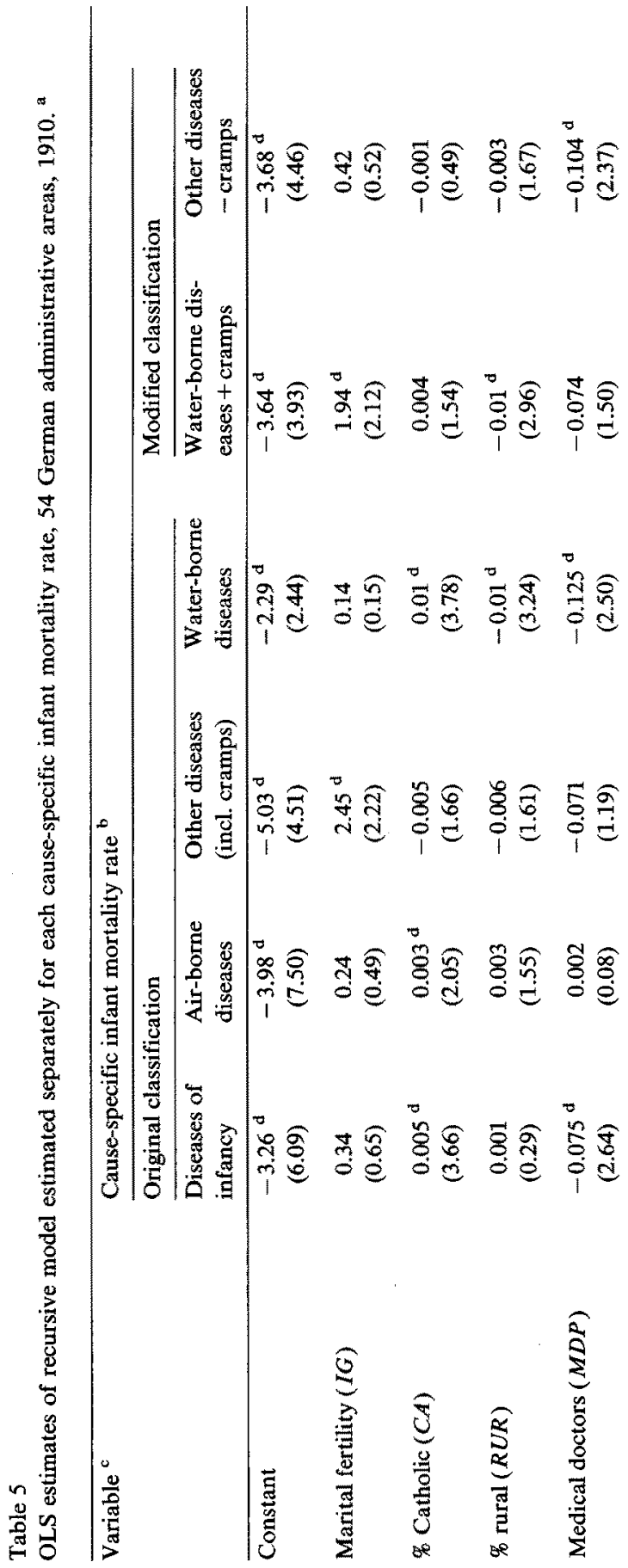




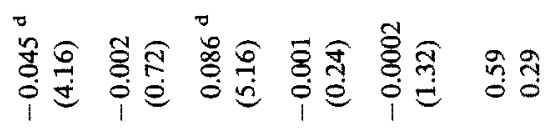

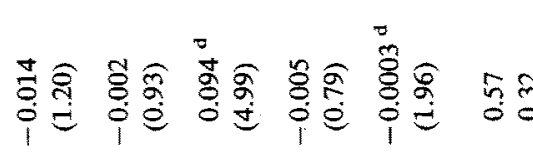

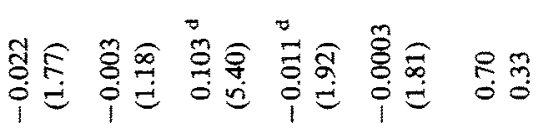

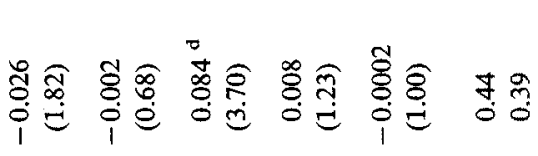

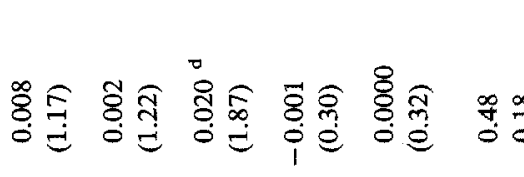

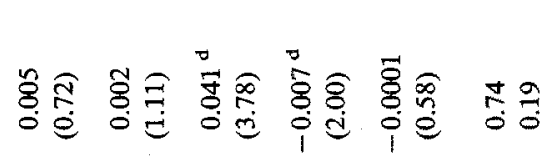

theng

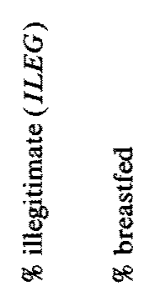

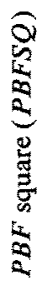


whose combined size is less than that of other variables. Thirdly, the impact of breastfeeding on the causes of death may be much less than that of the other factors.

To analyze these possibilities each cause-specific infant mortality rate, transformed as a logit, was regressed on the variables in equation $\mathrm{C}$ of table 3. The following discussion focuses on which causes of death the explanatory variables influence (as can be seen in the rows of table 5), rather than on which variables account for regional differences in each cause-specific infant mortality rate (which is shown in the columns of table 5).

The first possible explanation is examined by looking at the significance of the coefficients of the two breastfeeding terms in the equations for certain diseases of infancy and water-borne diseases without cramps, the causes of death most responsible for regional differences in infant mortality. Since the coefficients for percentage ever breastfed are significant, the first explanation can be discarded. Note that access to medical care, percentage Catholic, and percentage illegitimate also influence these causes of death.

Next, the impact of the various factors on the causes of death is examined. Breastfeeding influences fewer causes of death than do percentage illegitimate or percentage Catholic. Contrary to expectations, there is no association between breastfeeding and air-borne diseases. Percentage illegitimate affects all cause-specific infant mortality rates, including air-borne diseases and other causes of death with cramps, which are not influenced by breastfeeding. Percentage Catholic affects air-borne diseases in addition to those affected by breastfeeding. Access to medical care influences only those causes that breastfeeding does. These results partly support the second explanation.

The third possible explanation is examined by calculating the impact of breastfeeding on certain diseases of infancy and water-borne diseases, using $\mathrm{d} I M R$ (for each cause), standardized coefficients and elasticities. As with infant mortality from all causes combined, the impact of changes in breastfeeding are less than those of access to medical care and percentage illegitimate. An increase of one unit in percentage ever breastfed reduces infant mortality from certain diseases of infancy $(C D I)$ by 0.23 but a corresponding increase in percentage illegitimate raises it by 1.46 while a one unit increase in access to medical care lowers it by 2.55 . Similarly for water-borne diseases, a one per cent increase in percentage ever breastfed lowers infant mortality 
by 0.51 while an increase in percentage illegitimate raises it by 0.87 and an increase in access to medical care lowers it by 5.78 .

When the relative importance of variables is measured by standardized regression coefficients, the results are identical to those for $\mathrm{d} I M R$. However, when viewed in terms of elasticities, percentage ever breastfed has a slightly larger impact on mortality from certain diseases of infancy than do access to medical care or illegitimacy, as well as a slightly larger effect on mortality from water-borne diseases than does access to medical care. Results using elasticities differ from those based on standardized coefficients because the elasticity for percentage ever breastfed is inflated by its large mean relative to those of the causespecific infant mortality rates. ${ }^{15}$

These conclusions are little affected if the modified classification is used in place of the original classification. The only major changes are that access to medical care influences other diseases without cramps instead of water-borne diseases without cramps and marital fertility affects water-borne diseases with cramps instead of other diseases with cramps. ${ }^{16}$

This section has shown that breastfeeding contributes less to regional differences in infant mortality than do access to medical care and illegitimacy for two reasons. Its impact on the two chief causes of death, water-borne diseases without cramps and certain diseases of infancy, is less than the impact of the other two factors. In addition, it influences fewer causes of death than does the percentage illegitimate although it influences the same number as access to medical care.

\section{Discussion}

This paper has examined the impact of regional differences in breastfeeding on infant mortality patterns in Germany around 1910.

\footnotetext{
${ }^{15}$ Elasticity is the product of $\mathrm{d} I M R$ and the ratio of the mean of the explanatory variable to the mean of the dependent variable [Stolzenberg (1979)].

${ }^{16}$ The impact of the way that cramps were classified was examined by adding a dummy variable to the equations in table 5. This variable was scored one if the cramps category was used in that administrative area and zero otherwise. After controlling for the other factors affecting infant mortality, the administrative areas using the cramps category had higher mortality from other diseases (with cramps) and lower mortality for water-borne diseases without cramps than other areas did. These differences remained after moving some of the deaths away from other diseases and into water-borne diseases, as was done in the modified classification. These findings show that the correction procedure over-compensated for the cramps classification.
} 
Several conclusions have been reached. First, the prevalence of breastfeeding is strongly negatively related to infant mortality and remains so after controlling for public health measures and social, economic, and demographic factors that also influence infant mortality. The relationship between breastfeeding and infant mortality is quadratic, indicating that prolonged breastfeeding beyond six months reduces infant mortality even further than shorter durations.

Despite the statistical significance of its effect, breastfeeding has much less impact on infant mortality than do several other determinants of infant mortality, including access to medical care, percentage illegitimate, and marital fertility. Little specification bias results when percentage ever breastfed is omitted from the regression equation. This result can be expected to hold where the level, variability, and importance of breastfeeding, as well as its associations with other variables, are similar to those in Germany around $1910 .^{17}$

The relatively weak impact of breastfeeding was unexpected since examination of the cause-of-death structure revealed that water-borne diseases, which are strongly influenced by breastfeeding, accounted for most of the regional differences in infant mortality. Analysis indicated that breastfeeding contributes less to overall infant mortality because its impact on the various cause-specific infant mortality rates is weaker than that of the other factors. In addition, percentage illegitimate has a stronger impact than breastfeeding because it influences all causes of death while breastfeeding affects only half of them.

What are the implications of these findings? This paper supports the contention that the impact of breastfeeding on infant mortality may have been exaggerated in earlier studies [Palloni and Tienda (1986)]. Many of these studies did not control for other social, economic, and medical factors that also influence infant mortality.

Other researchers have argued about the importance of breastfeeding for explaining regional differences in infant mortality. This paper supports Lesthaeghe's (1963) contention that while Vandenbroeke et al. (1983) credited breastfeeding with explaining too much of regional differences in infant mortality in the Netherlands and Belgium, it cannot be completely dismissed, as Hofstee (1983) has asserted. It also suggests that factors influencing mortality chances among individuals

17 I am grateful to an anonymous reviewer for pointing this out to me. 
should not be assumed to have identical impact on mortality rates among populations.

Lastly, these findings must be viewed in the light of the possibly unique conditions in Germany, where regional differences in both the prevalence and duration of breastfeeding were pronounced. Breastfeeding patterns in other European countries may not have been as diverse as those in Germany. Furthermore, the substitutes for breastmilk used in Germany, particularly the wheat gruel and the early attempts at infant formulae, were not as common in other European countries. Since the impact of breastfeeding on infant mortality depends upon the nutritional adequacy and sterility of alternative infant foods, our findings concerning impact of breastfeeding on infant mortality in Germany may not be transferable to other countries. Further research is needed on the impact of breastfeeding under varying circumstances.

\section{References}

Aykroyd, W.R. and J.P. Kevany, 1973, Mortality in infancy and early childhood in Ireland, Scotland, and England and Wales, 1871 to 1970, Ecology of Food and Nutrition 2, 11-19.

Beaver, M.W., 1973, Population, infant mortality, and milk, Population Studies 27, 243-254.

Bollen, K.A. and R.W. Jackman, 1985, Regression diagnostics: An expository treatment of outliers and influential cases, Sociological Methods and Research 13, 510-542.

Butz, W.P., H.P. Habicht, and J. DaVanzo, 1984, Environmental factors in the relationship between breastfeeding and infant mortality: The role of sanitation and water in Malaysia, American Journal of Epidemiology 119, 516-525.

Chandra, R.K., 1978, Immunological aspects of human milk, Nutrition Reviews 36, 265-272.

Condran, Gretchen and E. Crimmins-Gardner, 1978, Public health measures and mortality in U.S. cities in the late nineteenth century, Human Ecology 6, 27-54.

Cunningham, Alan S., 1981, Breastfeeding and morbidity in industrialized countries: An update, in: E. Jelliffe and P. Jelliffe, eds., Advances in international maternal and child health, Vol. 1 (Oxford University Press, Oxford) 128-168.

DaVanzo, Julie and J.P. Habicht, 1986, Infant mortality decline in Malaysia, 1946-1975: The roles of changes in variables and changes in the structure of relationships, Demography 23 , $143-160$.

Davis, Kingsley, 1963, The theory of change and response in modern demographic history, Population Index 29, 245-366.

Dorneddon, Hans, 1928, Das berufsmässig tätige Heil- und Pflegepersonal im Deutschen Reich am 1. Mai 1927, Reichsgesundheitsblatt 3, no. 43, 690-705.

Dorneddon, Hans, 1935, Das im Deutschen Reiche berufsmässig tätige Heil- und Pflegepersonal am 1. Januar 1934, Reichsgesundheitsblatt 10, no. 7, 134-141.

Espenshade, T., 1973, The cost of children in the urban United States, Population Monograph, no. 14 (Institute of International Studies, University of California, Berkeley, CA).

Frey, Gottfried, 1923, Public health services in Germany (League of Nations, Health Organization). 
Galle, O. and W.R. Gove, 1978, Overcrowding, isolation and human behavior: Exploring the extremes and population distribution, in: K.C. Taeuber, L. Bumpass, and J.A. Sweet, eds., Social demography (Academic Press, New York) 95-132.

Germany, Statistisches Reichsamt, 1877, Die Ärzte und das medizinische Hülfspersonal, die Apotheken, und die Heilanstalten, sowie die wissenschaftlich medizinischen und pharmazeutischen Vereine im Deutschen Reich nach dem Bestande vom 1. April 1876, Monatshefte zur Statistik des Deutschen Reichs, Sept., 1-42.

Germany, Reichsgesundheitsamt, 1889, Die Verbreitung des Heilpersonals, der pharmazeutischen Anstalten und des pharmazeutischen Personals im Deutschen Reich nach den amtlichen Erhebungen vom 1. April 1887 (Springer, Berlin).

Germany, Reichsgesundheitsamt, 1901, Die Verbreitung des Heilpersonals im Deutschen Reich, Medizinal-statistische Mitteilungen aus dem Kaiserlichen Gesundheitsamt 6, 1*-19*.

Germany, Kaiserliches Gesundheitsamt, 1910, Die Verbreitung des Heilpersonals, der pharmazeutischen Anstalten und des pharmazeutischen Personals im Deutschen Reich nach dem amtlichen Erhebungen vom 1. Mai 1909, Medizinal-statistische Mitteilungen aus dem Kaiserlichen Gesundheitsamte 15, $1^{*}-109 *$.

Habicht, J.P., J. DaVanzo, and W.P. Butz, 1986, Does breastfeeding really save lives or are apparent benefits due to biases?, American Journal of Epidemiology 123, 279-290.

Hofstee, G.W., 1983, Geboorten, zuigelingenvoeding en zuigelingensterfte in hun regionale verscheidenheid in de 19e eeuw, Bevolking en Gezin Supplement 2, 7-60.

Jason, J.M., P. Nieburg, and J.S. Marks, 1984, Mortality and infectious disease associated with infant feeding practices in developing countries, Pediatrics, Supplement on Task Force on Infant Feeding Practices, 702-727.

Jellife, D.B. and E.J.P. Jellife, 1978, Human milk in the modern world (Oxford University Press, New York).

Joreskog, K.G. and D. Sorbom, 1978, LISREL IV: An analysis of linear structural relations by the method of maximum likelihood (International Educational Services, Chicago, IL).

Keller, Anton, 1911, Ein Führer durch Deutschlands Fürsorgeeinrichtungen zum Schutze des Säuglings, Zeitschrift für Säuglingsschutz 3, 284-312.

Kintner, Hallie J., 1982, The determinants of infant mortality in Germany from 1871 to 1933 , Unpublished Ph.D. dissertation (University of Michigan, Ann Arbor, MI).

Kintner, Hallie J., 1985, Trends and regional differences in breastfeeding in Germany from 1871 to 1937 , Journal of Family History 10, 163-182.

Kintner, Hallie J., 1986, Classifying causes of death in the late nineteenth and early twentieth centuries: The case of German infant mortality, Historical Methods 19, 45-54.

Kmenta, Jan, 1971, Elements of econometrics (Macmillan, New York).

Knodel, John E., 1974, The decline of fertility in Germany, 1871-1939 (Princeton University Press, Princeton, NJ).

Knodel, John E., 1975, Ortsippenbücher als Daten für die Historische Demographie, Gesellschaft und Geschichte 1, 288-324.

Knodel, John E., 1977, Breastfeeding and population growth: Assessing the demographic impact of changing infant feeding practices in the Third World, Science 198, 1111-1115.

Knodel, John and E. van de Walle, 1967, Breastfeeding, fertility and infant mortality: An analysis of some early German data, Population Studies 21, 109-131.

Lang, J., 1929, Die Hauptergebnisse der Erhebung über die Wasserversorgung in Bayern nach dem Stande von 1. Januar 1928, Bericht des Bayerischen Landesamts für Wasserversorgung über die bisherige 50jährige Tätigkeit 1878-1928 (Oldenburg, Munich) 147-153.

Lechtig, A., H. Delgado, R. Martorell, D. Richardson, D. Yarbrough and R. Klein, 1978, Effect of maternal nutrition on infant mortality, in: W.H. Mosley, ed., Nutrition and human reproduction (Academic Press, New York) 47-68. 
Lesthaeghe, R., 1983, De borstvoeding als verklaring voor regionale verschillen in vruchtbaarheid en zuigelingensterfte; Nederland en België in het midden van de XIXe eeuw, Bevolking en Gezin Supplement 2, 61-84.

McKeown, T., 1976, The modern rise of population (Academic Press, New York).

Palloni, Alberto and Marta Tienda, 1986, The effects of breastfeeding and pace of childbearing on mortality at early ages, Demography $23,31-52$.

Petersen, Trond, 1985, A comment on presenting results from logit and probit models, American Sociological Review 50, 130-131.

Pohlen, Kurt, 1936, Gesundheitsstatistisches Auskunftsbuch für das Deutsche Reich (Schoetz, Berlin) (Veröffentlichungen aus dem Gebiete der Medizinalverwaltung, 46).

Preston, Samuel H., 1976, Mortality patterns in national populations (Academic Press, New York).

Preston, Samuel H., ed., 1978, The effects of infant and child mortality on fertility (Academic Press, New York).

Preston, S.H. and E. van de Walle, 1978, Urban French mortality in the nineteenth century, Population Studies 32, 275-298.

Prinzing, F., 1931, Handbuch der medizinischen Statistik, Second edition (Fischer, Jena).

Reves, Randall, 1985, Declining fertility in England and Wales as a major cause of the twentieth century decline in mortality. The role of changing family size and age structure in infectious disease mortality in infancy, American Journal of Epidemiology 122, 112-126.

Richards, Toni, 1977, Fertility decline in Germany: An econometric appraisal, Population Studies $31,537-553$.

Rott, F., 1929, Der Rückgang der Säuglingssterblichkeit, in: A. Grotjahn, L. Langstein and F. Rott, eds., Ergebnisse Soziale Hygiene und Gesundheitsfürsorge 1 (Thieme, Leipzig) 85-134.

Salomon, H., 1906, Die städtische Abwasserbeseitigung in Deutschland (Fischer, Jena).

Seutemann, Karl, 1913, Säuglingsnährung und Säuglingssterblichkeit nach Ernährungsweise in der Stadt Hannover, in: Kommittee zur Ermittlung der Säuglingsnährung in Hannover-Linden, Säuglingsnährung, Säuglingssterblichkeit und Säuglingsschutz in den Städten Hannover und Linden (Selbstverlag, Berlin) 34-97.

Shorter, E., J. Knodel and E. van de Walle, 1971, The decline of non-marital fertility in Europe, 1880-1940, Population Studies 25, 375-393.

Spree, R., 1978, Die Entwicklung der differentiellen Säuglingssterblichkeit in Deutschland seit der Mitte des 19. Jahrhunderts, Paper presented at the International Colloquium on Man and Health in History, Berlin, Free University, under the direction of A.E. Imhof.

Stolzenberg, R.M., 1979, The measurement and decomposition of causal effects in nonlinear and nonadditive models, in: K.F. Schüssler, ed., Sociological methodology 1980 (Jossey-Bass, San Francisco, CA) 459-488.

United Nations, Department of Social Affairs, Population Division, 1954, Foetal, infant, and early childhood mortality, ST/SOA/Series A, Population Studies 13 (United Nations, New York).

Vandenbroeke, C., F. van Poppel and A.M. van der Woude, 1983, De zuigelingen en kindersterfte in België en Nederland in seculair perspectief, Bevolking en Gezin Supplement 2, 85-115.

Van Ginneken, J., 1974, Prolonged breastfeeding as a birth spacing method, Studies in Family Planning 5, 201-206.

Woodbury, R.M., 1925, Causal factors in infant mortality, Children's Bureau Publication no. 142 (US Department of Labor, Washington, DC). 